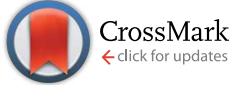

Cite this: RSC Adv., 2017, 7, 3117
Received 19th October 2016 Accepted 21st November 2016

DOI: 10.1039/c6ra25491h

www.rsc.org/advances

\section{Porous silver coating fiber for rapidly screening organotin compounds by solid phase microextraction coupled with surface enhanced Raman spectroscopy $\dagger$}

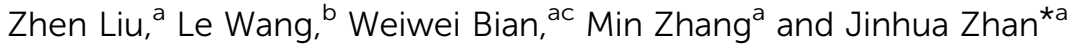

Preclinical research reveals the risk of organotin compounds (OTCs) as potent endocrine disruptors, immunotoxicants and environmental obesogens for mammals. OTCs are commercial antifungal agents which are found extensively in clothing, female hygiene products and childcare articles. OTCs have been listed as restricted chemicals by REACH Regulation (Annex XVII). Here, a hyphenated method combining surface enhanced Raman spectroscopy (SERS) with solid phase microextraction (SPME) is proposed for rapid screening of OTCs. A porous Ag layer was synthesized in situ and served as the SERS-active SPME coating for adsorption. The SERS spectra of trimethyltin chloride, tributyltin chloride and triphenyltin chloride were investigated, the bands at $554 \mathrm{~cm}^{-1}, 1410 \mathrm{~cm}^{-1}$ and $999 \mathrm{~cm}^{-1}$, respectively, being selected as the characteristic peaks for quantitative determination. The extraction conditions were optimized. The good stability and uniformity of porous Ag fibers insure a high enhancement factor of 9.1 $\times 10^{5}$ and low LOD of $0.2 \mathrm{ppb}$ for triphenyltin chloride. The proposed method was successfully applied to identify a mixture of OTCs in a textile matrix with satisfactory results.
\end{abstract}

\section{Introduction}

Organotin compounds (OTCs) are highly toxic and persistent chemicals with potential bioaccumulation. ${ }^{1}$ OTCs, and especially tributyltin, can perform as agonists for nuclear retinoid $\mathrm{X}$ receptors (RXR). This represses the transcription in target genes, eventually blocking many hormonal signals and regulatory pathways within the cells, ${ }^{2,3}$ such as lipid homeostasis and adipogenesis. ${ }^{4,5}$ OTCs have been listed as endocrine disruptors, immunotoxicants, and potent environmental obesogens for mammals. ${ }^{6}$ OTCs are commercial antifungal agents, PVC stabilizers and catalysts for the manufacture of consumer products, e.g., textiles, clothing, female hygiene products, childcare articles and toys. ${ }^{7-9}$ The intake of OTCs by a baby may, via skin contact with a diaper or chewing of soft toys and clothing, induce possible impairment of the central nervous system, immune system and reproductive system even at low concentrations. ${ }^{10}$ Consequently, the European Commission Directive 2009/425/EC has restricted the maximum

${ }^{a}$ Key Laboratory of Colloid and Interface Chemistry, Ministry of Education, Department of Chemistry, Shandong University, Jinan 250100, China. E-mail: jhzhan@sdu.edu.cn

${ }^{b}$ Center of Technology, Jinan Entry-Exit Inspection and Quarantine Bureau of the People's Republic of China, Jinan 250014, China

'Department of Pharmacy, Weifang Medical University, Weifang 261053, China

$\dagger$ Electronic supplementary information (ESI) available. See DOI: 10.1039/c6ra25491h concentration of dibutyltin (DBT), dioctyltin (DOT) and trisubstituted organotin in all consumer products to not more than $0.1 \%$ by weight of tin. These compounds are listed as restricted substances in the Annex XVII to the REACH Regulation. ${ }^{11}$

Various methods have been developed for the identification and quantification of OTCs, e.g., gas chromatography (GC), ${ }^{12}$ high performance liquid chromatography (HPLC), ${ }^{13}$ capillary electrophoresis, ${ }^{14,15}$ fluorescence, ${ }^{16,17}$ colorimetric methods ${ }^{18}$ and atomic absorption spectra. ${ }^{19}$ Chromatography followed by mass spectrometry detection (MS, ICP-MS) is a conventional tool in the speciation analysis of OTCs, involving a derivatization procedure with sodium tetraethylborate.$^{20}$ In order to fulfill the regulatory demands (e.g., Water Framework Directive, 2000/ 60/EC, 2008/105/EC and 2013/39/EU), most methods have focused mainly on the monitoring of OCTs in environmental samples. ${ }^{21}$ On the one hand, this strategy is usually required for traditional sampling and laboratorial detection. On the other hand, recent trends have focused on simplifying the operational steps, and then developing rapid, highly sensitive and on-site methods which can meet the demands of product safety, market supervision and import \& export trading. ${ }^{22-24}$

Sampling techniques like liquid-liquid extraction (LLE), solid-phase extraction (SPE) and solid-phase microextraction (SPME) are effective, clean-up methods for organic sample extraction from a complex matrix. ${ }^{25}$ SPME is a speedy and efficient equilibrium extraction method, which has been proved to 
be a powerful pre-concentration procedure in OTCs analysis. $^{\text {26-28 }}$ SPME is based on the equilibrium distribution of a substance between the solvent and stationary phase on the supporting substrate. The stationary phase is usually composed of a thin coating layer of sorbent material, which plays a crucial role in the extraction and desorption process. ${ }^{29}$ On the other hand, the properties of the coating will determine the performance of extraction. Porous materials have unique properties, such as good porosity, large specific surface area, tunable polarity, and excellent mechanical and thermal stability, which make them very attractive as adsorbents in coating materials. ${ }^{30}$ Porous materials like silica, ${ }^{31}$ carbon, ${ }^{32,33}$ polymers, ${ }^{34,35}$ metalorganic frameworks (MOFs) $)^{36,37}$ and metals ${ }^{38-41}$ with excellent properties have been successfully used for fabrication of a highcapacity SPME coating layer.

Recently, the application of SPME coupled with surface enhanced Raman spectroscopy (SERS) has been proven to be an excellent technique, which integrates the pre-concentration and the sensitive identification in one step. The samples can be probed in situ using a portable Raman spectrometer, overcoming the need to transport them to the laboratory. ${ }^{\mathbf{4 2 , 4 3}}$

SERS is an ultrasensitive analytical method, which has been widely used in the detection of explosives, ${ }^{\mathbf{4 4 , 4 5}}$ illegal additives ${ }^{\mathbf{4 6 , 4 7}}$ and cultural properties, ${ }^{\mathbf{4 8}, 49}$ particularly in the analysis of environmental pollutants, e.g. POPs, ${ }^{50-52}$ pesticides, ${ }^{53-55}$ and harmful ions. ${ }^{56-58}$ SERS can provide the detail of fingerprint spectra under electromagnetic and chemical enhancement. The electromagnetic enhancement is related to the surface plasmon resonance, which mainly depends on the surface nanostructures of the substrate..$^{59,60}$ Various nanostructured noble metal substrates have been reported for improving the enhancement, such as nanoparticle colloids, nanowires, nano-arrays and nano-films. ${ }^{\mathbf{6 1 , 6 2}}$ While conventional electrochemical methods can provide an effective, stable and reproducible porous substrate for SERS, in particular, in analytical applications. ${ }^{63,64}$

In this article, a porous $\mathrm{Ag}$ layer was electrochemically synthesized in situ and served as the SERS-active substrate for an absorption-type SPME coating. The SERS responses of triphenyltin, tributyltin and trimethyltin on this nanostructure surface were investigated, and the extraction capacities for these OTCs were subsequently evaluated and the extraction parameters were optimized. A fast and in situ analysis method for OTCs was established through SPME coupled with SERS by a portable Raman spectrometer. The proposed method was successfully applied to the determination of OTCs in textile samples, and the results were validated by ICP-MS.

\section{Experimental}

\section{Chemicals}

Trimethyltin chloride, triphenyltin chloride, tributyltin chloride (analytical standards) were purchased from Aladdin chemicals Co. Ltd. Silver wire (ø $0.4 \mathrm{~mm}, 99.9 \%$ ) was purchased from Beijing nonferrous metal research institute. The organotins were dissolved in methanol (for HPLC, TEDIA®) to get a stock solution at $1.0 \mathrm{mM}$. Milli-Q water (18.2 $\mathrm{M} \Omega$ ) was used in all experiments.

\section{Preparation and characterization}

Electrochemical synthesis was performed on a Princeton ${ }^{\circledR}$ PARSTAT 4000 electrochemical workstation in a three-electrode system; silver wires (effective area $ø 0.4 \times 30 \mathrm{~mm}$ ), silver bucket, and SCE were employed as the working, auxiliary and reference electrode, respectively. The silver wires were firstly ultrasonically cleaned with acetone and ethanol to degrease them for $10 \mathrm{~min}$, and then washed with ultrapure water. The nanoporous silver structure was prepared by cyclic voltammetry (CV) as in previous methods. ${ }^{63}$ The silver wires were immersed into $0.1 \mathrm{M}$ $\mathrm{HCl}$ electrolyte for $\mathrm{CV}$ scanning from $-0.2 \mathrm{~V}$ to $+0.2 \mathrm{~V}$ at a rate of $25 \mathrm{mV} \mathrm{s}^{-1}$ for 15 cycles. The morphology of the prepared nanoporous layer was characterized by a scanning electron microscope (JEOL JSM-6700F), and the component was confirmed by EDS equipment (Oxford Instruments). The surface topography of the nanoporous layer was imaged by atomic force microscopy (Multimode, Veeco Instruments \& Bruker); the crystallinity was also determined by X-ray diffraction (XRD) using a Bruker D8 Advance X-ray diffractometer.

\section{Extraction and SERS analysis}

The SPME procedure was performed by immersing the nanoporous $\mathrm{Ag}$ fibers into $20 \mathrm{~mL}$ of extraction solution for $60 \mathrm{~min}$ without stirring at $25{ }^{\circ} \mathrm{C}$. After that, the SPME fibers were then directly introduced for SERS analysis. The Raman spectra were performed on an Ocean Optics QE Pro Raman Spectrometer with an excitation wavelength of $785 \mathrm{~nm}$, laser power of $100 \mathrm{~mW}$ and integration time of $1 \mathrm{~s}$. The influence of extraction temperature and static placing time on the extraction effect were optimized. The kinetic parameter was determined from time curves of equilibrium at different concentrations. Thermodynamic information was also obtained from the adsorption isotherm at different temperatures. The analytes were qualitatively identified through the molecular fingerprint peaks of SERS. Under the optimum conditions, a quantitative determination was established through the relationship between the concentration and the intensity of the most sensitive characteristic peak.

\section{Validation in a textile matrix}

The spiked sample was prepared by the following steps. $1.0 \mathrm{~g}$ of three types of textile (cotton, polyester, cotton/polyester blend, cut into pieces less than $5 \mathrm{~mm} \times 5 \mathrm{~mm}$ ) and $20.0 \mathrm{~mL}$ of standard working solutions of TMT, TBT and TPT were added into a $25.0 \mathrm{~mL}$ glass flask, separately. The textile samples were mixed thoroughly for $24 \mathrm{~h}$ to reach equilibration under stirring. After that, the solvent was removed by rotary evaporation, and the remaining textile samples were used for the extraction. ${ }^{23} 1.0 \mathrm{~g}$ of spiked textile samples were added into $50.0 \mathrm{~mL}$ of methanol, and treated by ultrasonic extraction with water cooling for $60 \mathrm{~min}$. Then, the mixture was filtrated, and $50.0 \mu \mathrm{L}$ of filtrate was diluted with water to reach a final volume of $20.0 \mathrm{~mL}$. These solutions were used for SPME-SERS analysis. ICP-MS (ThermoFisher Element XR) was also employed to validate the results for those target analytes. 


\section{Statistical analysis}

Principal component analysis (PCA) is a statistical procedure that uses an orthogonal transformation to convert a set of observations of possibly correlated variables into a set of values of linearly uncorrelated variables. PCA can reduce the dimensionality of the spectroscopic data, thus facilitating the discrimination of SERS spectra. In particular, isomers with very similar SERS bands can be effectively identified through a PCA procedure performed on their spectra. ${ }^{65,66}$ This was employed to discriminate TMT, TBT and TPT based upon their SERS spectral data. The spectra were firstly pre-treated by smoothing and baseline subtraction using the software LabSpec5 to improve the spectral quality. Then the spectra were input into the PCA procedure and compiled with MATLAB R2014a.

\section{Results and discussion}

\section{Fabrication and characterization of the porous $\mathrm{Ag}$ fiber}

The nanoporous Ag layer on the fiber was synthesized with electrochemical assistance by CV scanning from $-0.2 \mathrm{~V}$ to $0.2 \mathrm{~V}$ at $25 \mathrm{mV} \mathrm{s}^{-1}$ for 15 cycles in $0.1 \mathrm{M} \mathrm{HCl}$ electrolyte. The electrochemical response of the $\mathrm{Ag}$ wire is shown in Fig. S1.† The current $(I)$ and capacitance $(Q)$ of the $\mathrm{Ag}$ wire electrode increased as the scanning progressed. The oxidation peak can be observed at approximately $0.185 \mathrm{~V}$ in the anodic scan region, and the opposite redeposition peak was observed at $-0.095 \mathrm{~V}$ in the cathodic region ( $I-E$ curve). After 15 cycles, the value of $Q_{\mathrm{s}}$ (the charge summit) reached its maximum. This suggests that the local dissolution/redeposition equilibrium occurs on the $\mathrm{Ag}$ surface, and the effective surface area of $\mathrm{Ag}$ electrode reaches a maximum (Fig. S1B $\dagger$ ). The morphology and components of the prepared nanoporous layer were characterized by SEM and XRD analysis. Fig. 1A shows that the Ag fiber was covered with coralline nanoparticles, whose diameter is about 100-150 nm. These aggregated nanoparticles form the unconsolidated porous structure. The structure of the nanoparticles was characterized by XRD, and Fig. 1B shows that the main diffraction peaks were assigned to the (110), (220) and (311) of cubic phase $\mathrm{Ag}$ (standard card JCPDS no. 04-0783), which demonstrates that the silver nanoparticles have good crystallinity. The EDS spectrum also confirms that the porous layer consists mainly of elemental Ag (Fig. S2 $\dagger$ ). The surface topography of the nanoporous layer was characterized by AFM, as illustrated in Fig. 2. A $10 \mu \mathrm{m} \times 10 \mu \mathrm{m}$ area was imaged by $2 \mathrm{D}$ and $3 \mathrm{D}$ patterns, and the size distribution and RMS roughness were measured by particle and section analysis. The results give a mean diameter of about $150 \mathrm{~nm}$ and an RMS of $69.3 \mathrm{~nm}$, which demonstrate that the nanoporous layer was successfully synthesized by the electrochemical method.

\section{SERS performance of OTCs on porous Ag fiber}

To evaluate the capacity of this SERS-active porous Ag fiber for extraction, the fibers were immersed in a working solution of $10.0 \mu \mathrm{M}$ of TMT, $1.0 \mu \mathrm{M}$ of TBT and $1.0 \mu \mathrm{M}$ of TPhT for $60 \mathrm{~min}$ at $25{ }^{\circ} \mathrm{C}$, respectively. After extraction, SERS spectra were measured, as shown in Fig. 3. Fig. 3A shows the SERS spectrum
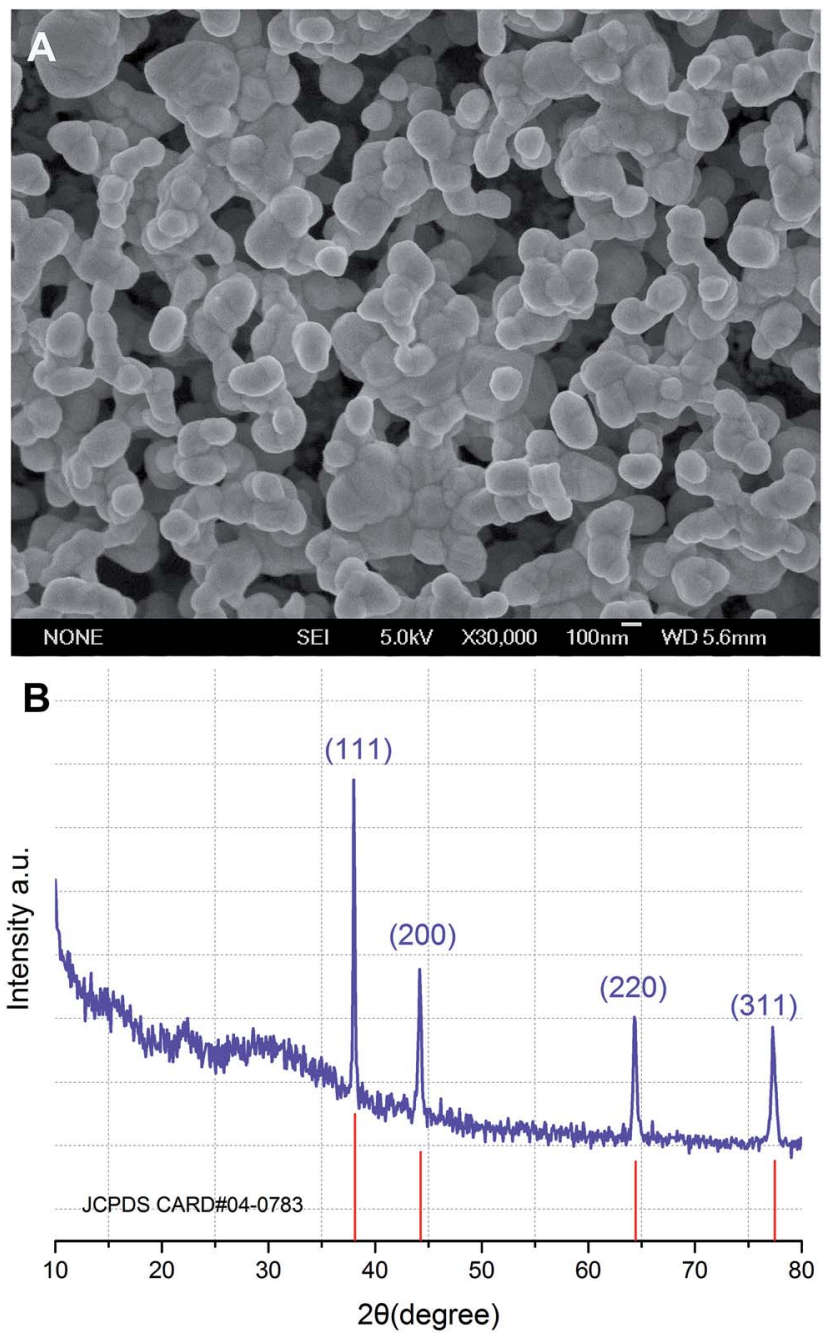

Fig. 1 (A) SEM image of porous layer on Ag fiber surface, (B) XRD pattern of porous Ag fiber compared with the standard JCPDS card no. 04-0783.
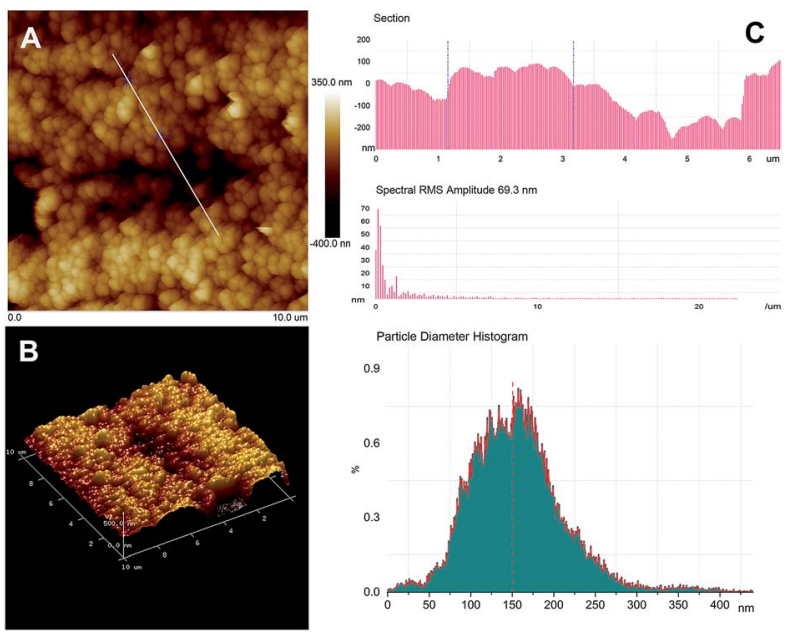

Fig. 2 The topographic map of porous layer Ag by AFM. (A) 2D pattern of $10 \mu \mathrm{m} \times 10 \mu \mathrm{m}$ area, (B) 3D pattern, (C) the histogram of sectionview, RMS roughness and particle size. 

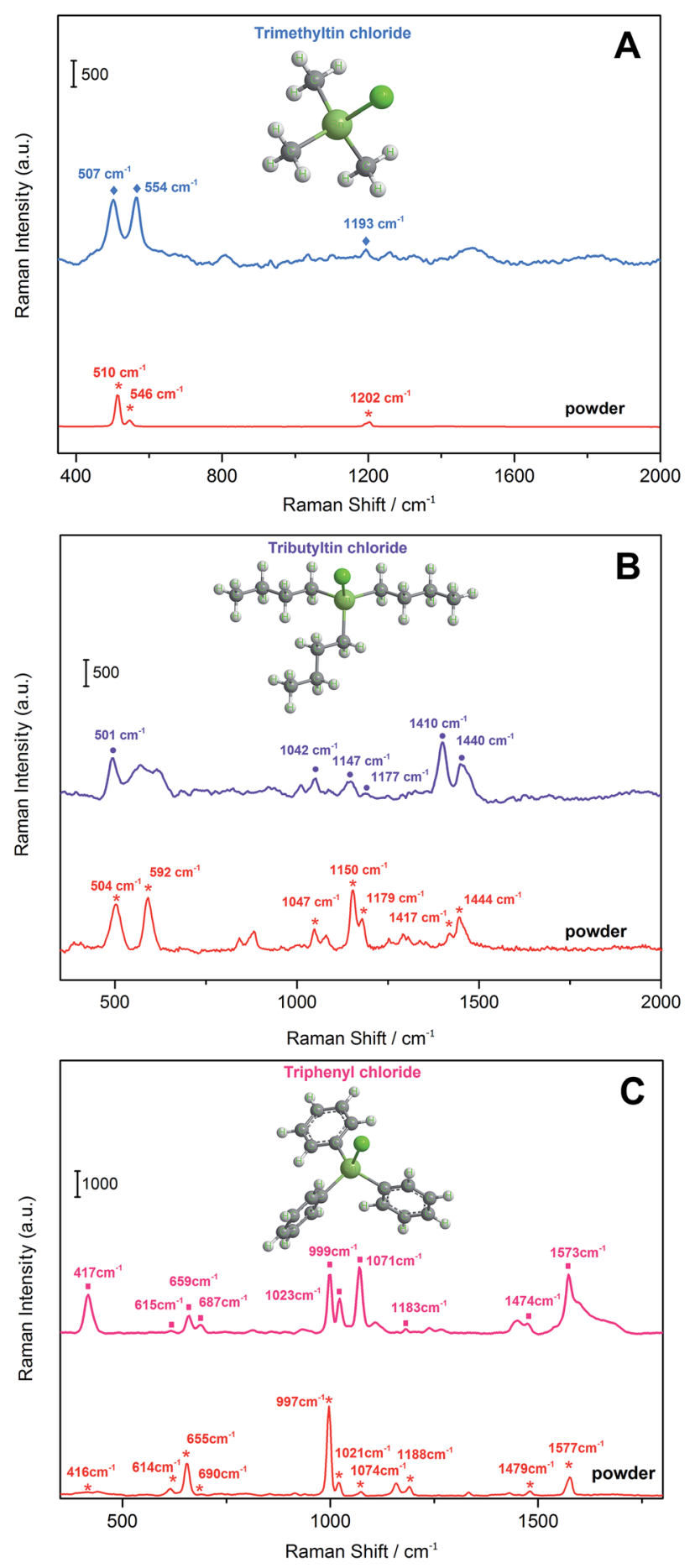

Fig. 3 SERS spectra of OTCs on porous Ag fiber. (A) The solution of $10.0 \mu \mathrm{mol} \mathrm{L} \mathrm{L}^{-1} \mathrm{TMT}$, (B) the solution of $1.0 \mu \mathrm{mol} \mathrm{L}{ }^{-1} \mathrm{TBT},(\mathrm{C})$ the solution of $1.0 \mu \mathrm{mol} \mathrm{L^{-1 }} \mathrm{TPhT}$. Raman spectra were measured with laser power $100 \mathrm{~mW}$, the integration time was $1 \mathrm{~s}$. Raman spectra of the solid powder are shown by red color at the bottom of each graphic.

of TMT on porous Ag substrate in the region from $400 \mathrm{~cm}^{-1}$ to $1800 \mathrm{~cm}^{-1}$. The SERS bands at $507 \mathrm{~cm}^{-1}, 554 \mathrm{~cm}^{-1}$ and 1193 $\mathrm{cm}^{-1}$ can be clearly identified, which is consistent with the Raman bands of TBT solid powder at $510 \mathrm{~cm}^{-1}, 546 \mathrm{~cm}^{-1}$ and $1205 \mathrm{~cm}^{-1} \cdot{ }^{67}$ For TBT in Fig. 3B, six obvious characteristic bands at $501 \mathrm{~cm}^{-1}, 1042 \mathrm{~cm}^{-1}, 1147 \mathrm{~cm}^{-1}, 1177 \mathrm{~cm}^{-1}, 1410 \mathrm{~cm}^{-1}$, and $1440 \mathrm{~cm}^{-1}$ were identified, and the corresponding Raman bands of solid powder were at $504 \mathrm{~cm}^{-1}, 1047 \mathrm{~cm}^{-1}, 1150 \mathrm{~cm}^{-1}$, $1179 \mathrm{~cm}^{-1}, 1417 \mathrm{~cm}^{-1}$, and $1444 \mathrm{~cm}^{-1} \cdot{ }^{68-70}$ The characteristic SERS bands of TPhT appear at $417 \mathrm{~cm}^{-1}, 615 \mathrm{~cm}^{-1}, 659 \mathrm{~cm}^{-1}$, $687 \mathrm{~cm}^{-1}, 999 \mathrm{~cm}^{-1}, 1023 \mathrm{~cm}^{-1}, 1071 \mathrm{~cm}^{-1}, 1183 \mathrm{~cm}^{-1}, 1474$ $\mathrm{cm}^{-1}$, and $1573 \mathrm{~cm}^{-1}$, which agrees well with the Raman spectrum of the solid powder (Fig. 3C). ${ }^{71,72}$ The assignment of the vibrational bands is shown in Table $\mathrm{S} 1 . \dagger$ The characteristic SERS bands at $554 \mathrm{~cm}^{-1}$ (TMT), $1410 \mathrm{~cm}^{-1}$ (TBT) and $999 \mathrm{~cm}^{-1}$ (TPhT) were assigned to the $\nu_{\text {as }}(\mathrm{Sn}-\mathrm{C}), \nu_{\text {as }}(\mathrm{C}-\mathrm{C})$ and $\nu_{\mathrm{s}-\text { as }}$ (phenyl ring breathing), respectively. These results indicate that organotin could be extracted and detected simultaneously on the surface of porous Ag fibers using SERS spectra.

The rate of dissolution/redeposition was mainly determined by the scan rate in the electrochemical redox reaction. The increase in scan rate would produce a high over-potential on the electrode surface, which can speed the electron transport between the $\mathrm{Ag}$ electrode and the electrolyte solution. ${ }^{73}$ The SERS enhancement response of porous Ag substrate under different scan rates was investigated in TMT, TBT and TPhT solutions, respectively. Fig. $\mathrm{S} 3 \dagger$ shows that the SERS intensity increases as the scan rate ranges from $5 \mathrm{mV} \mathrm{s}^{-1}$ to $100 \mathrm{mV} \mathrm{s}^{-1}$. The characteristic SERS bands (TMT $554 \mathrm{~cm}^{-1}$, TBT $1410 \mathrm{~cm}^{-1}$ and TPhT $999 \mathrm{~cm}^{-1}$ ) reach a maximum at $25 \mathrm{mV} \mathrm{s}^{-1}$. The enhancement factor was also calculated for different substrates according to the characteristic SERS intensity. The variation in enhancement effect can be attributed to the density of local hotspots and uniformity on SERS-active substrate (Fig. S4 $\uparrow$ ). The SEM images of different porous Ag layers show that the particle size decreases as the scan rate increases, so the aggregation from small particles can supply more hotspots for a large enhancement of the Raman signal. On other hand, when a high scan rate $\left(75 \mathrm{mV} \mathrm{s}^{-1}\right)$ was implemented, the electrode reaction would be mainly controlled by the diffusion step; rapid electron transport would result in cavitation damage in local places; and the uniformity of the porous layer would become worse. Consequently, $25 \mathrm{mV} \mathrm{s}^{-1}$ was selected in the following experiments for strong SERS enhancement.

\section{Stability, uniformity and reproducibility}

The stability, uniformity and reproducibility are crucial properties of a SERS-active substrate, which insure the accuracy and precision of signals in quantitative detection. Firstly, the stability of the fiber under laser irradiation was evaluated. SERS spectra of OTCs were continuously measured for $120 \mathrm{~s}$ (sampling interval $2 \mathrm{~s}$ ) with a laser power of $100 \mathrm{~mW}$. As shown in Fig. 4A, there is no obvious change in SERS intensity under $120 \mathrm{~s}$ of continuous irradiation. The RSD of characteristic SERS band intensity changes at $554 \mathrm{~cm}^{-1}$ (TMT), $1410 \mathrm{~cm}^{-1}$ (TBT) and $999 \mathrm{~cm}^{-1}$ (TPhT) were $3.05 \%, 5.27 \%$ and $4.87 \%$, which indicates an acceptable stability for routine SERS analysis.

Secondly, the uniformity was investigated by measuring Raman spectra along the axial and radial directions on the $\mathrm{Ag}$ fiber surface, with sampling intervals of $3.0 \mathrm{~mm}$ and $0.3 \mathrm{~mm}$, respectively. The number of sampling points for each substrate 
A
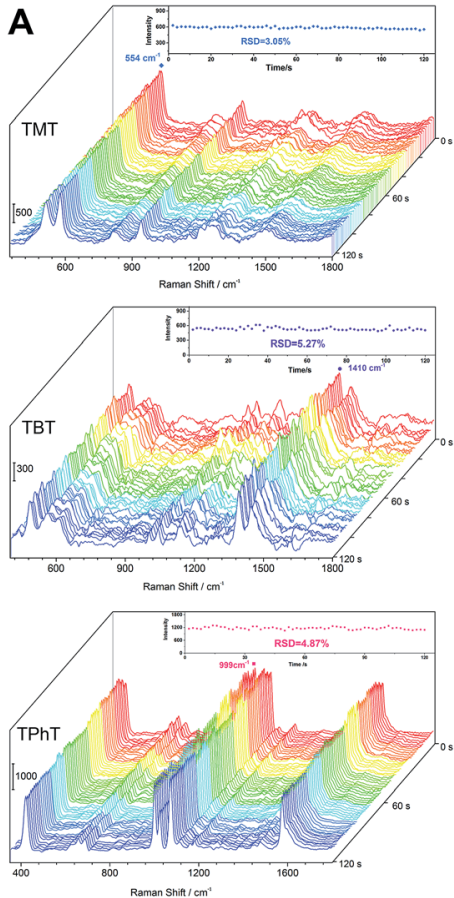

B
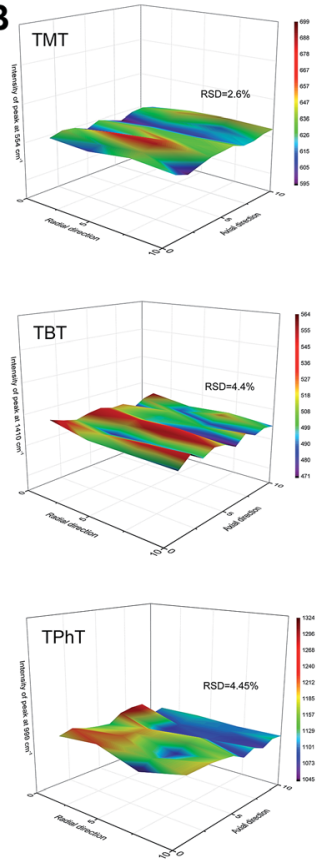

Fig. 4 (A) The stability of the substrate probed with OTCs under $120 \mathrm{~s}$ of continuous laser irradiation. The inset plot shows the intensity change of characteristic bands at $554 \mathrm{~cm}^{-1}\left(10.0 \mu \mathrm{mol} \mathrm{L}^{-1} \mathrm{TMT}\right), 1410$ $\mathrm{cm}^{-1}(1.0 \mu \mathrm{mol} \mathrm{L}-1 \mathrm{TBT})$ and $999 \mathrm{~cm}^{-1}\left(1.0 \mu \mathrm{mol} \mathrm{L}{ }^{-1} \mathrm{TPhT}\right)$, respectively. (B) The uniformity of the fiber along the axial and radial directions, the characteristic band intensity was mapped in a 3D pattern.

was 40 sites. The characteristic band intensities of TMT, TBT and TPhT were selected for mapping in a 3D pattern, as illustrated in Fig. 4B. The RSDs of the SERS band intensity were $2.6 \%$ (TMT), $4.4 \%$ (TBT) and 4.45\% (TPhT), suggesting the good uniformity of the substrate.

The reproducibility of porous Ag fibers was also evaluated by comparing the SERS spectra after extraction and elution. Firstly, the extraction was performed in solution for $100 \mathrm{~min}$ to reach equilibrium. After SERS measurement, the porous $\mathrm{Ag}$ fibers were desorbed by ultrasonic cleaning for $1 \mathrm{~min}$ in methanol, and the SERS spectrum of the blank fibers was finally recorded, as shown in Fig. S5. $\uparrow$ The fibers have good reproducibility in six cycles. The RSDs of the characteristic band intensities were $5.5 \%$ (TMT), $4.6 \%$ (TBT) and 2.6\% (TPhT).

\section{Optimization of extraction}

The optimization of the extraction temperature was evaluated. The influence of temperature on extraction was investigated. As shown in Fig. S6, $\uparrow$ the intensity of the characteristic band decreased as the temperature increased from $25{ }^{\circ} \mathrm{C}$ to $60{ }^{\circ} \mathrm{C}$. Traditionally, the adsorption of a molecule on a solid surface is generally an exothermic process. To gather more information, the adsorption was determined at different temperatures. As shown in Fig. $\mathbf{S 7}, \dagger$ the isotherm curve closely approximated to type I. On the other hand, according to the fitted results, the isotherm curve agrees well with the Langmuir adsorption formula in aqueous solution. ${ }^{74}$

$$
w=\frac{k_{\mathrm{e}} w_{\mathrm{s}} C_{\mathrm{a}}}{\left(1+k_{\mathrm{e}} C_{\mathrm{a}}\right)}
$$

where $w$ is the surface adsorption quantity, $w_{\mathrm{s}}$ is the saturated surface adsorption quantity, $C_{\mathrm{a}}$ is the concentration of adsorbate in solution, $k_{\mathrm{e}}$ is the adsorption equilibrium constant at a certain temperature. If the reciprocals of formula (1) are taken, it can be expressed as:

$$
\frac{1}{w}=\frac{1}{w_{\mathrm{s}}}+\frac{1}{k_{\mathrm{e}} w_{\mathrm{s}}} \times \frac{1}{C_{\mathrm{a}}}
$$

When $1 / w$ is plotted versus $1 / C_{\mathrm{a}}$, the $k_{\mathrm{e}}$ can be calculated from the intercept and slope. The SERS intensity was explained by the following formula: ${ }^{75}$

$$
I_{\mathrm{SERS}} \propto N I_{\mathrm{L}}\left|A\left(\nu_{\mathrm{L}}\right)\right|^{2}\left|A\left(\nu_{\mathrm{S}}\right)\right|^{2} \sigma_{\mathrm{ads}}^{\mathrm{R}}
$$

$I_{\text {SERS }}$ is the SERS intensity, $N$ is the number of adsorption molecules involved in the SERS process, $I_{\mathrm{L}}$ is the excitation intensity, $A\left(\nu_{\mathrm{L}}\right)$ and $A\left(\nu_{\mathrm{S}}\right)$ are excitation and scattered field enhancement factors, $\sigma_{\text {ads }}^{\mathrm{R}}$ is the increased Raman cross section of the adsorbed molecule.

$I_{\text {SERS }} \propto w$

In consequence, the SERS intensity is proportional to the surface adsorption quantity in the Langmuir adsorption model. According to the plot of $1 / I_{\text {SERS }}$ versus $1 / C_{\mathrm{a}}$, the $k_{\mathrm{e}}$ was calculated from the intercept and slope and listed in Table S2. $\dagger$ The adsorption equilibrium constant decreases as the extraction temperature rises, which demonstrates that the adsorption of OTCs on the porous Ag surface is generally an exothermic process.

The effect of extraction time on detection was investigated, and the kinetic curves for different concentrations of TMT, TBT and TPhT were determined. As shown in Fig. $S 8, \uparrow$ the saturated adsorption times were $60 \mathrm{~min}$ and $40 \mathrm{~min}$ for low and high concentrations, respectively. The lower the concentration of the sample, the longer the time required to reach adsorption equilibrium. Hence, an extraction time of $60 \mathrm{~min}$ was selected to ensure that the adsorption of porous $\mathrm{Ag}$ fibers reaches equilibrium. Under the optimal conditions, saturated adsorption curves were determined by immersing the porous $\mathrm{Ag}$ fibers into solutions of TMT (10.0 $\mu \mathrm{mol} \mathrm{L}^{-1}$ to $\left.10 \mathrm{nmol} \mathrm{L}^{-1}\right)$, TBT (1.0 $\mu \mathrm{mol} \mathrm{L}{ }^{-1}$ to $\left.0.1 \mathrm{nmol} \mathrm{L}^{-1}\right)$ and TPhT $\left(1.0 \mu \mathrm{mol} \mathrm{L}^{-1}\right.$ to $0.05 \mathrm{nmol}$ $\mathrm{L}^{-1}$ ), respectively. The SERS spectra and adsorption curves (the intensity of characteristic band $v s$. the solution concentration) are shown in Fig. S9. $\uparrow$ The Raman intensity of the characteristic band was saturated at higher concentrations. This could be attributed to the saturation adsorption of molecules on surface hotspots.

\section{Quantitative detection of OTCs in a textile matrix}

The quantitative detection of TMT, TBT and TPhT in a textile matrix was performed as in the above described steps. The 
textile sample was spiked and pre-extracted in methanol. Then the mixture was filtrated, and the filtrate was diluted with water to prepare the solution for SPME-SERS analysis. Fig. 5 shows the Raman intensity of TMT at $554 \mathrm{~cm}^{-1}$, which increases linearly with the concentration ranging from $1.0 \mu \mathrm{mol} \mathrm{L}{ }^{-1}$ to $0.05 \mu \mathrm{mol}$ $\mathrm{L}^{-1}$. The correlation coefficient $\left(R^{2}\right)$ was 0.9850 , and the limit of detection (LOD) was $6.9 \mathrm{ppb}$. The linear relationship of TBT at $1410 \mathrm{~cm}^{-1}$ ranges from $0.1 \mu \mathrm{mol} \mathrm{L}{ }^{-1}$ to $5.0 \mathrm{nmol} \mathrm{L}^{-1}$. The $R^{2}$ was 0.9807 , and the LOD was $1.1 \mathrm{ppb}$. Meanwhile, the linear relationship of TPhT at $999 \mathrm{~cm}^{-1}$ ranges from $0.1 \mu \mathrm{mol} \mathrm{L}{ }^{-1}$ to $3.0 \mathrm{nmol} \mathrm{L}{ }^{-1}$. The $R^{2}$ was 0.9910 , and the LOD was low at $0.2 \mathrm{ppb}$.

To evaluate the capacity of porous $\mathrm{Ag}$ fibers to identify complex organotin in a textile sample, the sample was spiked with TMT $\left(1.0 \mu \mathrm{mol} \mathrm{L}{ }^{-1}\right)$, TBT $\left(0.1 \mu \mathrm{mol} \mathrm{L}{ }^{-1}\right)$ and TPhT $(30.0$ nmol L ${ }^{-1}$ ) simultaneously. The extraction was performed at $25{ }^{\circ} \mathrm{C}$ for $60 \mathrm{~min}$. As shown in Fig. 6, the SERS spectra of OTC mixtures indicate that the characteristic bands at $410 \mathrm{~cm}^{-1}, 653$ $\mathrm{cm}^{-1}, 999 \mathrm{~cm}^{-1}, 1022 \mathrm{~cm}^{-1}, 1071 \mathrm{~cm}^{-1}$, and $1570 \mathrm{~cm}^{-1}$ (the rose red squares) are assigned to the characteristic bands of triphenyltin chloride; the bands at $598 \mathrm{~cm}^{-1}, 1151 \mathrm{~cm}^{-1}, 1174$ $\mathrm{cm}^{-1}, 1410 \mathrm{~cm}^{-1}$ and $1440 \mathrm{~cm}^{-1}$ (the purple dots) are assigned to the characteristic bands of tributyltin chloride; the band at $509 \mathrm{~cm}^{-1}$ (the blue diamonds) is identified as the characteristic band of trimethyltin chloride. Compared with the SERS spectra of single organotin (Fig. 3), the $\nu_{\mathrm{s}}(\mathrm{Sn}-\mathrm{Cl})$ and $\nu(\mathrm{Sn}-\mathrm{C})$ bands of TPhT in the mixtures shift negatively from $417 \mathrm{~cm}^{-1}$ and 659 $\mathrm{cm}^{-1}$ to $410 \mathrm{~cm}^{-1}$ and $653 \mathrm{~cm}^{-1}$, respectively. The $\delta\left(\mathrm{CH}_{3}\right)$ bands
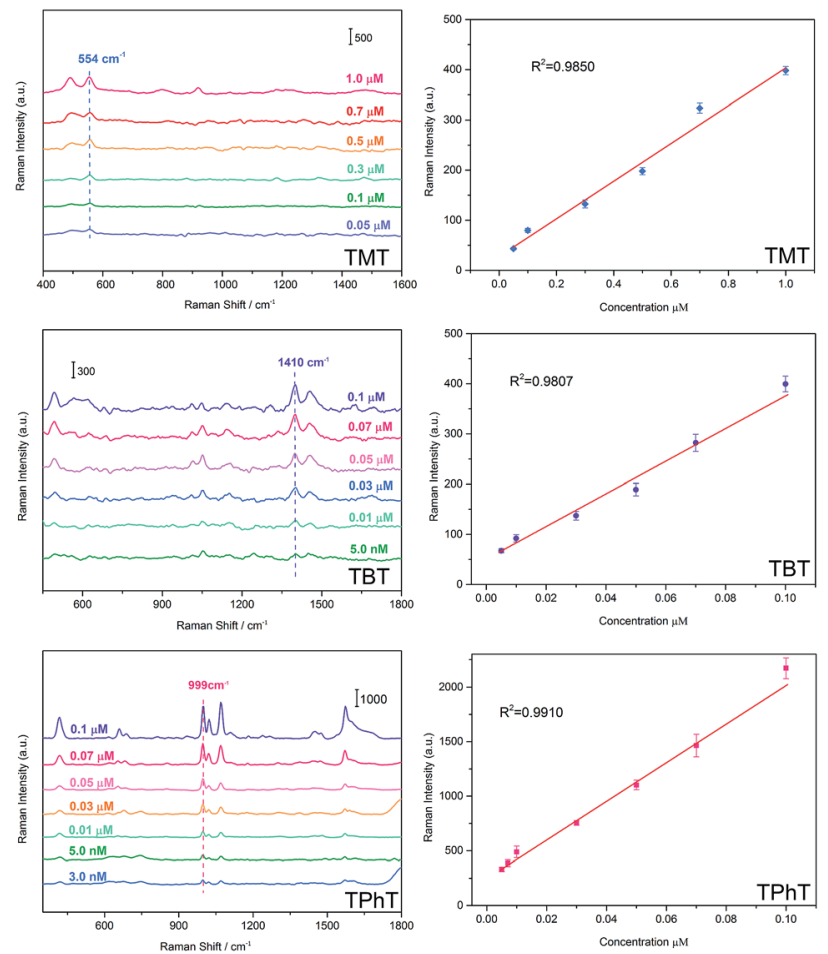

Fig. 5 SERS spectra of OTCs with different concentration in the spiked textile sample and the calibration curves for TMT, TBT and TPhT, respectively. The error bar of points was obtained from six replicated determination.
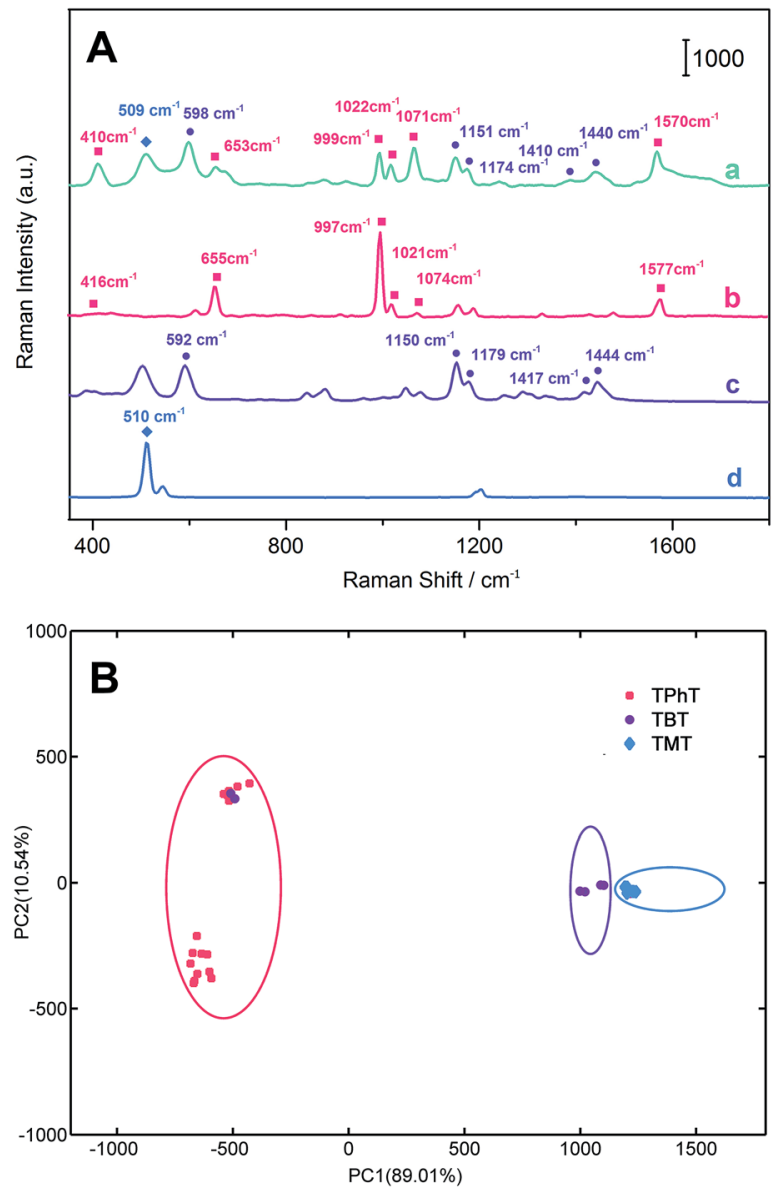

Fig. 6 (A) The SERS spectra of the mixture containing $1.0 \mu \mathrm{mol} \mathrm{L^{-1 }}$

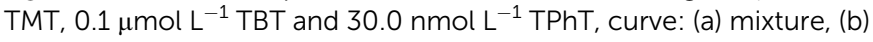
(TPhT powder), (c) (TBT powder), (d) (TMT powder). (B) PCA plots for the characteristic bands of mixture.

of TBT shift positively from $1147 \mathrm{~cm}^{-1}$ to $1151 \mathrm{~cm}^{-1}$, and a clear $\nu(\mathrm{Sn}-\mathrm{C})$ band appears at $598 \mathrm{~cm}^{-1}$. The $\nu_{\mathrm{S}}(\mathrm{Sn}-\mathrm{C})$ band of TMT shifts positively from $507 \mathrm{~cm}^{-1}$ to $509 \mathrm{~cm}^{-1}$, and the $\nu_{\text {as }}(\mathrm{Sn}-\mathrm{C})$ band at $554 \mathrm{~cm}^{-1}$ disappears. The change in peaks in the low wavenumber region may be attributed to the vibronic coupling of the $\mathrm{Sn}-\mathrm{C}$ band. The co-attachment of OTC molecules can induce emission band overlap and shows significant intermolecular communication between these moieties. ${ }^{76,77}$ These results indicate that the mixtures of OTCs had been extracted and detected by porous Ag fibers. The PCA results also reveal that the TMT, TBT and TPhT can be clearly discriminated by the analysis of SERS characteristic bands in Fig. 6B. Finally, the conventional ICP-MS method was also employed to validate the results for those target analytes that are listed in Table $\mathrm{S} 3 \dagger$ for comparison.

\section{Conclusions}

In conclusion, the SERS-active porous $\mathrm{Ag}$ layer was electrochemically synthesized and fabricated as an SPME fiber for rapid determination of OTCs in a textile matrix. The SERS responses of TMT, TBT and TPhT on porous Ag fibers were 
investigated, and the extraction conditions were optimized. The isotherm revealed that the adsorption of OTCs on porous Ag fibers agreed well with the Langmuir type in aqueous solution. The variation of $k_{\mathrm{e}}$ with temperature suggests a spontaneous exothermic process. The good stability and uniformity insure the accuracy and precision of signals in quantitative detection. The high enhancement factors of $1.36 \times 10^{5}, 9.0 \times 10^{5}$ and 9.1 $\times 10^{5}$, and then the low LODs of $6.9 \mathrm{ppb}, 1.1 \mathrm{ppb}$ and $0.2 \mathrm{ppb}$ were obtained for TMT, TBT and TPhT, respectively. The SPMESERS method combines the advantages of pre-concentration and high sensitivity, which promote the potential for rapid screening of OTCs in consumer product safety of import \& export trading.

\section{Acknowledgements}

We are grateful for financial support from National Basic Research Program of China (973 Program 2013CB934301) and National Natural Science Foundation of China (NSFC21377068, 21575077). Weiwei Bian acknowledges financial support from Shandong Provincial Natural Science Foundation (ZR2015BL020). Le Wang acknowledges support from general administration of Quality Supervision, Inspection and Quarantine of the People's Republic of China (2015IK212), the National Major Research Program of China (2016YFF0203704).

\section{Notes and references}

1 A. C. A. Sousa, M. R. Pastorinho, S. Takahashi and S. Tanabe, Environ. Chem. Lett., 2014, 12, 117-137.

2 B. Julius and D. Zdenek, Curr. Drug Metab., 2011, 12, 71-88.

3 J. Brtko, Biomed. Pap., 2007, 151, 187-194.

4 F. Grun and B. Blumberg, Rev. Endocr. Metab. Disord., 2007, 8, 161-171.

5 J. Brtko and Z. Dvorak, Toxicol. Lett., 2015, 234, 50-58.

6 A. Giusti and C. Joaquim-Justo, Comp. Biochem. Physiol., Part C: Toxicol. Pharmacol., 2013, 158, 187-198.

7 Survey of chemical substances in consumer products, No. 90, 2008, http://www2.mst.dk/udgiv/publications/2008/978-877052-717-0/pdf/978-87-7052-718-7.pdf, accessed March 2008.

8 Toxic chemicals in a child's world: an investigation into PVC plastic products, http:/www.greenpeace.org/international/ Global/international/planet-2/report/2001/5/toxic-chemicalsin-a-child-s-w.pdf, accessed June 2001.

9 Health risk assessment for organotins in textiles, http://rivm.openrepository.com/rivm/bitstream/10029/9609/ 1/613350002.pdf, accessed March 2000.

10 A. Pagliarani, S. Nesci and V. Ventrella, Toxicol. in Vitro, 2013, 27, 978-990.

11 REACH, Annex XVII in Decision 2009/425/EC of the European Parliament and of the Council, Official Journal of the European Union, 2009.

12 A. Valenzuela, G. Lespes, W. Quiroz, L. F. Aguilar and M. A. Bravo, Talanta, 2014, 125, 196-203.

13 W. Gui, C. Tian, Q. Sun, S. Li, W. Zhang, J. Tang and G. Zhu, Water Res., 2016, 95, 185-194.
14 S. Jing, B. He, Y. G. Yin, L. Lu and G. B. Jiang, Anal. Methods, 2010, 2, 2025-2031.

15 G. D. Yang, J. H. Xu, L. J. Xu, G. N. Chen and F. F. Fu, Talanta, 2010, 80, 1913-1918.

16 Y. Niu, F. Han, Q. Zhang, T. Xie, L. Lu, S. Li and H. Xia, Angew. Chem., Int. Ed., 2013, 52, 5599-5603.

17 S. H. Li, F. R. Chen, Y. F. Zhou, J. N. Wang, H. Zhang and J. G. Xu, Chem. Commun., 2009, 28, 4179-4181.

18 Y. F. Zhou, J. N. Wang, S. H. Li and J. G. Xu, Analyst, 2010, 136, 282-284.

19 L. Průša, J. Dědina and J. Kratzer, Anal. Chim. Acta, 2013, 804, 50-58.

20 R. F. Cole, G. A. Mills, R. Parker, T. Bolam, A. Birchenough, S. Kröger and G. R. Fones, Trends Environ. Anal. Chem., 2015, 8, 1-11.

21 J. Richter, I. Fettig, R. Philipp, N. Jakubowski, U. Panne, P. Fisicaro and E. Alasonati, J. Chromatogr. A, 2016, 1459, 112-119.

22 N. Campillo, P. Viñas, R. Peñalver, J. I. Cacho and M. Hernández-Córdoba, J. Food Compos. Anal., 2012, 25, 66-73.

23 L. Zhang, X. Luo, Z. Niu, X. Ye, Z. Tang and P. Yao, J. Chromatogr. A, 2015, 1386, 22-30.

24 Methodology for recommending analytical methods to check compliance with REACH Annex XVII restrictions, https:// www.echa.europa.eu/documents/10162/13577/methodology_ analytical_methods_en.pdf, accessed March 2016.

25 J. R. Dean, Pre-concentration and Clean-up Procedures for Organic Sample Extracts, John Wiley \& Sons, Ltd, 2013.

26 C. Moscoso-Pérez, V. Fernández-González, J. MoredaPiñeiro, P. López-Mahía, S. Muniategui-Lorenzo and D. Prada-Rodríguez, J. Chromatogr. A, 2015, 1385, 85-93.

27 S. Noventa, J. Barbaro, M. Formalewicz, C. Gion, F. Rampazzo, R. B. Brusà, M. Gabellini and D. Berto, Anal. Chim. Acta, 2015, 858, 66-73.

28 B. M. Manuel, V. S. Aníbal, F. P. Edwar and Q. V. Waldo, J. Chromatogr. A, 2012, 1223, 9-14.

29 G. Ouyang and J. Pawliszyn, Principle and Application of Solid Phase Microextraction, Chemical Industry Press, Beijing, 2012.

30 P. Liu and G. Chen, Porous Materials: Processing and Applications, Butterworth-Heinemann, Oxford, 2014.

31 J. G. Hou, Q. Ma, X. Z. Du, H. L. Deng and J. Z. Gao, Talanta, 2004, 62, 241-246.

32 F. Zhu, J. Guo, Z. Feng, R. Fu, D. Wu, T. Luan, Y. Tong, T. Lu and G. Ouyang, J. Chromatogr. A, 2010, 1217, 78487854.

33 Y. Lin, L. Wu, K. Xu, Y. Tian, X. Hou and C. Zheng, Chem.Eur. J., 2015, 21, 13618-13624.

34 E. Turiel and A. Martín-Esteban, Anal. Chim. Acta, 2010, 668, 87-99.

35 M. Szultkamlynska, P. Olszowy and B. Buszewski, Crit. Rev. Anal. Chem., 2015, 2012, 3955-3958.

36 X. Y. Cui, Z. Y. Gu, D. Q. Jiang, Y. Li, H. F. Wang and X. P. Yan, Anal. Chem., 2009, 81, 9771-9777.

37 N. Chang, Z. Y. Gu, H. F. Wang and X. P. Yan, Anal. Chem., 2011, 83, 7094-7101. 
38 H. L. Xu, Y. Li, D. Q. Jiang and X. P. Yan, Anal. Chem., 2009, 81, 4971-4977.

39 S. Sungkaew, C. Thammakhet, P. Thavarungkul and P. Kanatharana, Anal. Chim. Acta, 2010, 664, 49-55.

40 A. M. Hafez and B. W. Wenclawiak, Anal. Bioanal. Chem., 2013, 405, 1753-1758.

41 Y. X. Yang, M. Guo, Y. D. Zhang, W. L. Song, Y. Li, X. M. Wang and X. Z. Du, RSC Adv., 2015, 5, 71859-71867.

42 C. Liu, X. Zhang, L. Li, J. Cui, Y.-e. Shi, L. Wang and J. Zhan, Analyst, 2015, 140, 4668-4675.

43 S. Zhu, X. Zhang, J. Cui, Y.-e. Shi, X. Jiang, Z. Liu and J. Zhan, Analyst, 2015, 140, 2815-2822.

44 J. Wang, L. Yang, B. Liu, H. Jiang, R. Liu, J. Yang, G. Han, Q. Mei and Z. Zhang, Anal. Chem., 2014, 86, 3338-3345.

45 Y.-e. Shi, W. Wang and J. Zhan, Nano Res., 2016, 9, 24872497.

46 J. Chen, Y. Huang, P. Kannan, L. Zhang, Z. Lin, J. Zhang, T. Chen and L. Guo, Anal. Chem., 2016, 88, 2149-2155.

47 B. Liu, G. Han, Z. Zhang, R. Liu, C. Jiang, S. Wang and M.-Y. Han, Anal. Chem., 2012, 84, 255-261.

48 M. Leona, P. Decuzzi, T. A. Kubic, G. Gates and J. R. Lombardi, Anal. Chem., 2011, 83, 3990-3993.

49 A. Cesaratto, M. Leona, J. R. Lombardi, D. Comelli, A. Nevin and P. Londero, Angew. Chem., Int. Ed. Engl., 2014, 53, 1437314377.

50 H. Tang, G. Meng, Q. Huang, Z. Zhang, Z. Huang and C. Zhu, Adv. Funct. Mater., 2012, 22, 218-224.

51 L. Guerrini, J. V. Garciaramos, C. Domingo and S. Sanchezcortes, Anal. Chem., 2009, 81, 953-960.

52 X. Jiang, Y. Lai, W. Wang, J. Wei and J. Zhan, Talanta, 2013, 116, 14-17.

53 B. Liu, G. Han, Z. Zhang, R. Liu, C. Jiang, S. Wang and M. Y. Han, Anal. Chem., 2012, 84, 255-261.

54 J. Kubackova, G. Fabriciova, P. Miskovsky, D. Jancura and S. Sanchez-Cortes, Anal. Chem., 2015, 87, 663-669.

55 S. Pang, T. Yang and L. He, TrAC, Trends Anal. Chem., 2016, 85, 73-82.

56 K. Kim, K. L. Kim and K. S. Shin, Analyst, 2012, 137, 38363840.

57 C. Ruan, W. Wang and B. Gu, Anal. Chim. Acta, 2006, 567, 114-120.

58 R. A. Alvarez-Puebla and L. M. Liz-Marzán, Angew. Chem., Int. Ed., 2012, 51, 11214-11223.
59 S. Schlucker and W. Kiefer, Surface Enhanced Raman Spectroscopy: Analytical, Biophysical and Life Science Applications, Wiley-VCH, Weinheim, 2011.

60 E. C. L. Ru and P. G. Etchegoin, Principles of surface-enhanced Raman spectroscopy and related plasmonic effects, Elsevier, 2009.

61 B. Yan, A. Thubagere, W. R. Premasiri, L. D. Ziegler, N. L. Dal and B. M. Reinhard, ACS Nano, 2009, 3, 1190-1202.

62 J. Taylor, A. Huefner, L. Li, J. Wingfield and S. Mahajan, Analyst, 2016, 141, 5037-5055.

63 K.-H. Yang, Y.-C. Liu and C.-C. Yu, J. Mater. Chem., 2008, 18, 4849-4855.

64 M. E. Abdelsalam, P. N. Bartlett, J. J. Baumberg, S. Cintra, T. A. Kelf and A. E. Russell, Electrochem. Commun., 2005, 7, 740-744.

65 A. R. Campos, Z. Gao, M. G. Blaber, R. Huang, G. C. Schatz, R. P. Van Duyne and C. L. Haynes, J. Phys. Chem. C, 2016, 120, 20961-20969.

66 A. Kaminska, E. Witkowska, A. Kowalska, A. Skoczynska, P. Ronkiewicz, T. Szymborski and J. Waluk, Anal. Methods, 2016, 8, 4521-4529.

67 P. Chaudhary, M. Bieringer, P. Hazendonk and M. Gerken, Dalton Trans., 2015, 44, 19651-19658.

68 R. A. Cummins, Aust. J. Chem., 1963, 16, 985-988.

69 A. Szorcsik, L. Nagy, K. Gajda-Schrantz, L. Pellerito, E. Nagy and F. T. Edelmann, J. Radioanal. Nucl. Chem., 2002, 252, 523-530.

70 J. Wiss and A. Zilian, Org. Process Res. Dev., 2003, 7, 10591066.

71 S. Ramalingam, S. Periandy and S. Mohan, Spectrochim. Acta, Part A, 2010, 77, 73-81.

72 J. Jiang, J.-M. Gao, J.-S. Guo, Q.-H. Zhou, X.-H. Liu, W.-J. Ouyang, P. Zhang, W.-L. Fu, W. Zhang and S.-X. He, Chemosphere, 2016, 161, 96-103.

73 A. J. Bard and L. R. Faulkner, Electrochemical Methods: Fundamentals and Applications, Wiley-VCH, New York, 2nd edn, 2001.

74 S. Kondo, T. Ishikawa, I. Abe and G. Li, Adsorption Science, Chemical Industry Press, Beijing, 2nd edn, 2006.

75 K. Kneipp, H. Kneipp, I. Itzkan, R. R. Dasari and M. S. Feld, Chem. Rev., 1999, 99, 2957-2976.

76 J. R. Lombardi, R. L. Birke and G. Haran, J. Phys. Chem. C, 2011, 115, 4540-4545.

77 J. Cabalo, J. A. Guicheteau and S. Christesen, J. Phys. Chem. A, 2013, 117, 9028-9038. 